\title{
Spatial variability of soil water content and related factors across the Hexi Corridor of China
}

\author{
LI Xiangdong ${ }^{1,2}$, SHAO Ming'an ${ }^{1,2,3^{*}}$, ZHAO Chunlei ${ }^{3}$, JIA Xiaoxu $^{2,3}$ \\ ${ }^{1}$ State Key Laboratory of Soil Erosion and Dryland Farming on the Loess Plateau, Institute of Soil and Water Conservation, \\ Chinese Academy of Sciences and Ministry of Water Resources, Yangling 712100, China; \\ ${ }^{2}$ College of Natural Resources and Environment, University of Chinese Academy of Sciences, Beijing 100190, China; \\ ${ }^{3}$ Key Laboratory of Ecosystem Network Observation and Modeling, Institute of Geographic Sciences and Natural Resources \\ Research, Chinese Academy of Sciences, Beijing 100101, China
}

\begin{abstract}
Soil water content (SWC) is a key factor limiting ecosystem sustainability in arid and semi-arid areas of the Hexi Corridor of China, which is characterized by an ecological environment that is vulnerable to climate change. However, there is a knowledge gap regarding the large-scale spatial distribution of SWC in this region. The specific objectives of this study were to determine the spatial distribution patterns of SWC across the Hexi Corridor and identify the factors responsible for spatial variation of SWC at a regional scale. This study collected and analyzed SWC in the $0-100 \mathrm{~cm}$ soil profile from 109 field sampling sites (farmland, grassland and forestland) across the Hexi Corridor in 2017. We selected 17 factors, including land use, topography (latitude, longitude, elevation, slope gradient, and slope aspect), soil properties (soil clay content, soil silt content, soil bulk density, saturated hydraulic conductivity, field capacity, and soil organic carbon content), climate factors (mean annual precipitation, potential evaporation, and aridity index), plant characteristic (vegetation coverage) and planting pattern (irrigation or rain-fed), as possible environmental variables to analyze their effects on SWC. The results showed that SWC was 0.083 $( \pm 0.067) \mathrm{g} / \mathrm{g}$ in the $0-100 \mathrm{~cm}$ soil profile and decreased in the order of farmland, grassland and forestland. The SWC in the upper soil layers $(0-20,20-40$ and $40-60 \mathrm{~cm}$ ) had obvious difference when the mean annual precipitation differed by $200 \mathrm{~mm}$. The SWC decreased from southeast to northwest following the same pattern as precipitation, and had a moderate to strong spatial dependence in a large effective range (75-378 km). The SWC showed a similar distribution and had no significant difference between soil layers in the $0-100 \mathrm{~cm}$ soil profile. The principal component analysis showed that the mean annual precipitation, geographical position (longitude and latitude) and soil properties (soil bulk density and soil clay content) were the main factors dominating the variance of environmental variables. A stepwise linear regression equation showed that plant characteristic (vegetation coverage) and soil properties (soil organic carbon content, field capacity and soil clay content) were the optimal factors to predict the variation of SWC. Soil clay content could be better to explain the SWC variation in the deeper soil layers compared with the other factors.
\end{abstract}

Keywords: soil water content; spatial variability; geostatistical analysis; soil clay content; Hexi Corridor

Citation: LI Xiangdong, SHAO Ming'an, ZHAO Chunlei, JIA Xiaoxu. 2019. Spatial variability of soil water content and related factors across the Hexi Corridor of China. Journal of Arid Land, 11(1): 123-134. https://doi.org/10.1007/s40333-018-0123-x

\footnotetext{
*Corresponding author: SHAO Ming'an (E-mail: shaoma@igsnrr.ac.cn)

Received 2018-03-06; revised 2018-05-29; accepted 2018-06-07

(C) Xinjiang Institute of Ecology and Geography, Chinese Academy of Sciences, Science Press and Springer-Verlag GmbH Germany, part of Springer Nature 2019
} 


\section{Introduction}

Soil water content (SWC) is a vital component of the hydrological cycle and the major factor limiting ecosystem sustainability in arid and semi-arid areas. SWC is replenished by precipitation and determines the amount of evaporation and water uptake by vegetation, which impacts the water, energy and biogeochemical cycles (Seneviratne et al., 2010; McColl et al., 2017). Knowledge on spatial pattern of SWC is conducive to water resource management and ecosystem regulation (Moore et al., 2011; Jia et al., 2017a). Inputting SWC spatial patterns into hydrological models can reduce the uncertainty associated with simulating hydrological processes (Orth and Seneviratne, 2017; Wang and Cheung, 2017; Zhao and Dai, 2017).

The importance of SWC has been widely recognized in various spatial and temporal scales in China. Li and Ma (2015) identified that between 1951 and 2008, over 54.6\% of the total land area of Mainland China experienced drought, and that drought conditions occurred within $40.0 \%$ of the months over that period. Based on a model simulation, Xia et al. (2017) pointed out that the risk to water resources was severe in arid and semi-arid areas of China under the future climate change scenarios. A meta-analysis of 1740 observations in northern China reported that SWC decreased significantly when land use changed during restoration and plant age had no influence on SWC (0-100 cm depth) (Deng et al., 2016). Jia et al. (2017a) found that SWC within 0-500 $\mathrm{cm}$ soil depth decreased in the first 20-25 years following restoration and then recovered with increased stand age after afforestation on the Chinese Loess Plateau. At a regional scale, Wang et al. (2010a) studied spatial patterns of soil desiccation across the Chinese Loess Plateau and reported that the dried soil layer thickness was $160 \mathrm{~cm}$ and topographical factors (i.e., slope gradient) explained $39 \%$ of the total variance of soil desiccation. In the entire region of Xinjiang in Northwest China, SWC generally increased both in the shallow and deep layers from 1951 to 2000 and was closely related to precipitation, temperature and local heterogeneity (Zheng et al., 2017). Over a south-north transect $(860 \mathrm{~km})$ observation on the Chinese Loess Plateau, Zhang et al. (2017) and Zhao et al. (2017) reported that the SWC was lower than the stable field capacity at most of the sites and soil properties (i.e., soil clay content and field capacity) were the most correlated factors. Zhang et al. (2016) noted that the SWC in the 0-500 cm depth decreased with vegetation succession (about 160 years) and was significantly correlated with aeration porosity $(P<0.05)$ at five plots in a semi-humid area. SWC is also strongly influenced by tree species (Sonnenborg et al., 2017), understory vegetation (Mollnau et al., 2014), root mass (Wang et al., 2010b, 2013) and many other factors (Wu et al., 2015).

Few studies focused on understanding the SWC at a large scale across the Hexi Corridor. The Hexi Corridor is located in an arid and semi-arid area of Northwest China. The region is characterized by low precipitation, high evaporation, and serious aeolation and is sensitive to changes in climate (Liu, 2003; Xia et al., 2017; Zhang et al., 2017). The region is expected to face a high risk of drought and water scarcity in the next 20 years (Xia et al., 2017). Recent researches on soil water conditions across the Hexi Corridor often confined to small scales, such as inland river basins (Cheng et al., 2014; Sun et al., 2017; Yao et al., 2018). Zhang et al. (2017) investigated the SWC in an area of approximately $100 \mathrm{~km}^{2}$ in the Hexi Corridor and found that soil drought mainly occurred in the newly cultivated land and the desert-oasis ecotone. Compared with a desert and a wetland, SWC of a farmland had a great temporal stability in the middle reaches of the Heihe River (Li and Shao, 2015). The variation of SWC was high at an interannual scale from 2006 to 2014, while it remained stable at the intra-annual scale from March to November in the desert region of the Hexi Corridor (Niu et al., 2016).

Knowledge of SWC distribution across the Hexi Corridor is important for economic development and social services within the region. Based on the above considerations, we hypothesize that the spatial variability of SWC is strongly heterogeneous across the Hexi Corridor, and that SWC is strongly influenced by the local and climatic factors. A large-scale field sampling was conducted across the region to test these hypotheses. The specific objectives of this study were to (1) determine the spatial distribution patterns of SWC across the Hexi Corridor and (2) identify the factors responsible for spatial variation of SWC at a regional scale. 


\section{Materials and methods}

\subsection{Study area}

This study was conducted across the Hexi Corridor of Gansu Province in China $\left(35^{\circ} 45^{\prime}-42^{\circ} 47^{\prime} \mathrm{N}\right.$, $92^{\circ} 44^{\prime}-104^{\circ} 44^{\prime} \mathrm{E}$; $1000-3000 \mathrm{~m}$ a.s.1.; Fig. 1), which has a total area of $2.63 \times 10^{5} \mathrm{~km}^{2}$. The Hexi Corridor is a passage running in the southeast-northwest direction, which has Altun Mountains and Qilian Mountains in the south and Mazong Mountains, Heli Mountains and Longshou Mountains in the north, and deserts in the northeast (including Badain Jaran Desert and Tengger Desert). The Hexi Corridor starts at Wushaoling Mountain in the east and ends at Yumenguan in the west (Bao and Fang, 2007; Wu, 2016). The Shiyang River, Heihe River and Shule River are the three major river systems across the Hexi Corridor, with all the riverheads coming from the glaciers of Qilian Mountains.

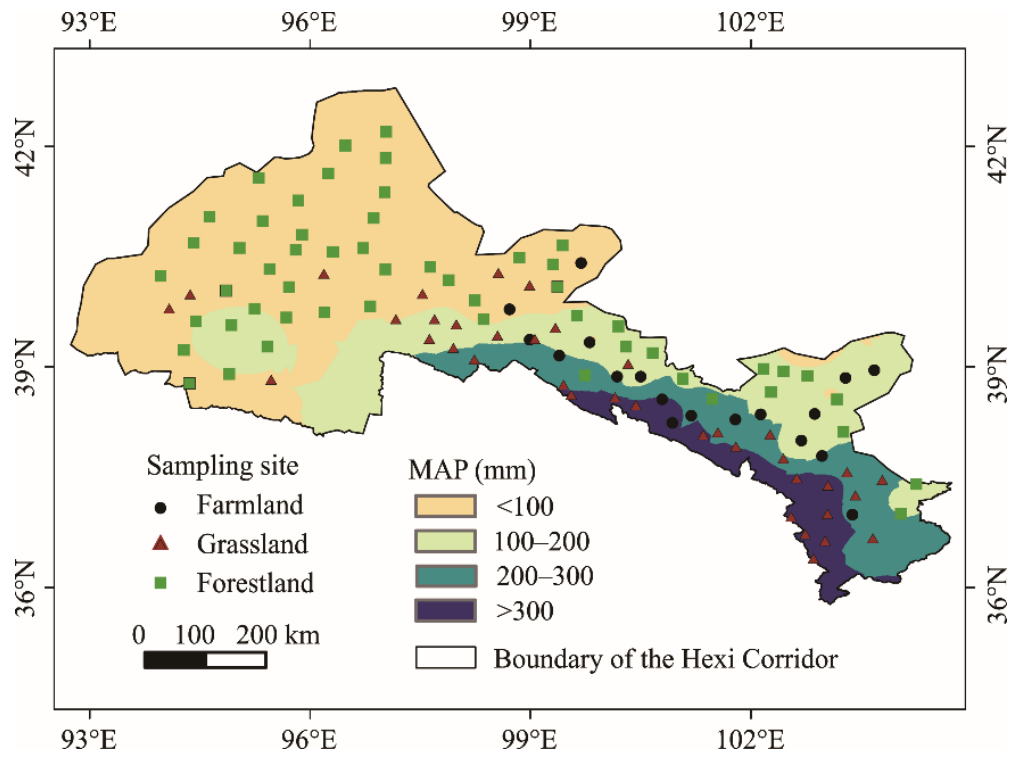

Fig. 1 Spatial distribution of field sampling sites (under three land uses of farmland, grassland and forestland) and mean annual precipitation (MAP)

The Hexi Corridor is characterized by an arid and semi-arid continental monsoon climate, with annual mean temperature (MAT) of $5^{\circ} \mathrm{C}-9^{\circ} \mathrm{C}$, mean annual evaporation of $1500-3200 \mathrm{~mm}$, mean annual precipitation (MAP) of $50-350 \mathrm{~mm}$, and $60 \%-70 \%$ of rainfalls occurring between June and September (Bao and Fang, 2007; Zhang et al., 2017). From the southeast to the northwest of the Hexi Corridor, soil textures include silt-sandy loam, loam, sandy loam, loamy sand and sandy soil according to the taxonomic system of United States Department of Agriculture. Soil thickness ranges from 0.2 to $1.5 \mathrm{~m}$ and the surface soil layers have high gravel content, particularly in the northwest area (Wang et al., 2014; Zhang et al., 2017). The farmland is mainly located proximate to cities and rivers. The forest is mainly planted to protect roads and farmland, and to improve the environment. The grassland and shrubland have been subjected to grazing prohibition since 2000 . The Hexi Corridor is subject to severe wind erosion, which leads to land degradation and loss of soil fertility. Vegetation species found in the region include Haloxylon ammodendron (C. A. Mey.) Bunge, Tamarix ramosissima Ledeb, Calligonum gobicum (Beg. ex Meisn.) A. Los., Nitraria sphaerocarpa Maxim, Reaumuria soongorica (Pall.) Maxim, Sympegma regelii Bunge, Stipa bungeana Trin and Humulus scandens (Lour.) Merr. Wheat and maize are the two major crops in the region.

\subsection{Field sampling}

From May to June, 2017, a total of 109 field sampling sites were investigated across the Hexi Corridor (Fig. 1). We set the field sampling sites under different categorical variables, such as 
land use (18 sites in the farmland, 37 sites in the grassland, and 54 sites in the forestland), MAP (46 sites in the areas with MAP $<100 \mathrm{~mm}, 33$ sites in the areas with MAP of 100-200 mm, 17 sites in the areas with MAP of $200-300 \mathrm{~mm}$, and 13 sites in the areas with MAP $>300 \mathrm{~mm}$ ) and planting pattern ( 9 sites in the areas through irrigation and 9 sites in the areas through rain-fed). The field sampling sites were predetermined on a digital topographic map and the distance between two adjacent sites was about $40 \mathrm{~km}$. They were located in the field using a GPS receiver. The sampling design could be considered partially randomized as the sites were randomly selected without prior knowledge of the site conditions (Wang et al., 2010a).

At each field sampling site, disturbed soil samples were collected with a soil auger $(5 \mathrm{~cm}$ in diameter and $25 \mathrm{~cm}$ in length). Undisturbed samples were obtained with a cutting ring $(5 \mathrm{~cm}$ in diameter and $5 \mathrm{~cm}$ in length). The soil profile was divided into five layers: 0-20, 20-40, 40-60, 60-80 and 80-100 cm. The sampling depth was restricted by bedrock, large rocks or stones in some mountainous areas. A total of 631 disturbed soil samples $(0-20,20-40,40-60,60-80$ and $80-100 \mathrm{~cm}$ depth) and 297 undisturbed soil cores (0-5 and 20-25 cm depth) were sealed and transported to the laboratory. The gravimetric SWC was measured from the weight loss during oven drying at $105^{\circ} \mathrm{C}$ to a constant mass.

\subsection{Measurement of related factors}

We selected 17 related factors, including land use, topography (LA, latitude; LO, longitude; EL, elevation; SG, slope gradient; SA, slope aspect), soil properties (CC, soil clay content; SC, soil silt content; BD, soil bulk density; Ks, saturated hydraulic conductivity; FC, field capacity; SOC, soil organic carbon content), climate factors (MAP; PE, potential evaporation; AI, aridity index), plant characteristic ( $\mathrm{VC}$, vegetation coverage) and planting pattern (irrigation or rain-fed), as possible environmental variables to analyze their effects on SWC. LA, LO and EL of the field sampling sites were recorded by a GPS receiver (GPSmap 60CSx, Garmin, MO, USA; 5 m precision in the horizontal direction). SG and SA were measured with a geological compass. VC was determined within a $10 \mathrm{~m} \times 10 \mathrm{~m}$ quadrat. $\mathrm{BD}, \mathrm{Ks}$ and $\mathrm{FC}$ were determined using the undisturbed soil core samples. Specifically, BD was determined using the core method by weighing the undisturbed soil core samples with a volume of $100 \mathrm{~cm}^{3}$ after oven-drying at $105^{\circ} \mathrm{C}$. Ks was measured using the constant-water-head method (Klute and Dirksen, 1986). FC (volumetric water content at $-1 / 3$ bar) was estimated by a SWC retention curve (Ratliff et al., 1983). The disturbed soil samples were air-dried and sieved through a 1-mm mesh for soil texture analysis and a $0.25-\mathrm{mm}$ mesh for measurements of SOC. CC $(<0.002 \mathrm{~mm})$ and SC $(0.002-0.050$ $\mathrm{mm}$ ) were measured by a laser particle analyzer (Mastersizer 2000, Malvern Instruments, Malvern, England). SOC was measured using dichromate oxidation (external heat application) method (Bao, 2000). MAP, PE and AI of the field sampling sites were extracted from climate grid maps at $500 \mathrm{~m} \times 500 \mathrm{~m}$ resolution. The climate data sets (1980-2015) were provided by the Data Center for Resources and Environmental Sciences, Chinese Academy of Sciences (RESDC) (http://www.resdc.cn). Irrigation was applied on farmland to increase the survival rate of crops. We differentiated the irrigation and rain-fed farmland by talking with locals and observing irrigation equipment. The measurement methods of all the environmental variables were described in detail in previous researches (Wang et al., 2010a; Zhao et al., 2017).

\subsection{Statistical analysis}

Basic summary statistics for SWC including minimum, maximum, mean, standard deviation (SD), coefficient of variation (CV), skewness and kurtosis were calculated in the 0-20, 20-40, 40-60, 60-80 and 80-100 cm soil layers. In addition, basic summary statistics for SWC in the $0-100 \mathrm{~cm}$ soil profile is the average of those in the $0-20,20-40,40-60,60-80$ and $80-100 \mathrm{~cm}$ soil layers. One-sample Kolmogorov-Smirnov Test and log transformations were used to check and satisfy normality. Homogeneity of variance test, one-way ANOVA and nonparametric Mann-Whitney $U$ tests were used to compare the mean difference in SWC between categorical variables. The correlations between SWC and related factors were tested by Pearson test. Principle component analysis (PCA) was used to conduct dimensionality reduction of variables 
after Kaiser-Meyer-Olkin and Bartlett's tests. The principle component (PC) was selected when the eigenvalue was larger than 1 . The first principle component (PC 1) has the greatest variance on the first coordinate, the second principle component (PC 2) has the second greatest variance on the second coordinate, and so on. Variance inflation factor (VIF) was used to measure the multicollinearity between variables. Stepwise linear regression was used to quantify the relationships between SWC and significantly related factors. Variables was entered (or removed) from the model depending on the significance (probability) of the $F$ values at 0.05 (or 0.1 ). Raw data were processed using a Gauss-Kruger projection coordinate system for geostatistical analysis. Semivariograms were calculated to quantify the spatial structure of SWC and provide input parameters for spatial interpolation using ordinary kriging method. Traditional statistical analyses were performed using Excel 2007 (Microsoft Corporation, Redmond, WA, USA), SPSS package (Version 16.0, CHI, USA) and SigmaPlot (Version 12.5, Systat Software, CA, USA). GS+ (Version 9.0, Gamma Design Software, LLC, MN, USA) and ArcGIS (Version 10.2, ESRI Inc., CA, USA) were used to perform geostatistical analysis and produce maps.

\section{Results and discussion}

\subsection{Spatial variability of SWC}

\subsubsection{Statistical analysis}

The summary statistics for SWC in the $0-100 \mathrm{~cm}$ soil profile are shown in Table 1 . The values of SWC in various soil depths ranged from 0.002 to $0.450 \mathrm{~g} / \mathrm{g}$, with $0.083( \pm 0.067) \mathrm{g} / \mathrm{g}$ in the $0-100$ $\mathrm{cm}$ soil profile across the Hexi Corridor. The maximum value of SWC was $0.450 \mathrm{~g} / \mathrm{g}$ in the $20-40$ $\mathrm{cm}$ layer. The coefficient of variation of SWC in different layers ranged from $80.4 \%$ to $90.8 \%$, indicating a moderate variability of SWC (Shao et al., 2006). The one-sample Kolmogorov-Smirnov Test showed that the values of SWC were log-normally distributed in various depths.

Table 1 Summary statistics for soil water content (SWC) across the Hexi Corridor in various soil depths

\begin{tabular}{cccccccccc}
\hline Depth $(\mathrm{cm})$ & $n$ & Minimum $(\mathrm{g} / \mathrm{g})$ & Maximum $(\mathrm{g} / \mathrm{g})$ & Mean $(\mathrm{g} / \mathrm{g})$ & SD $(\mathrm{g} / \mathrm{g})$ & $\mathrm{CV}(\%)$ & Skewness & Kurtosis & DT \\
\hline $0-100$ & 109 & 0.006 & 0.374 & 0.083 & 0.067 & 80.4 & 1.36 & 2.41 & Log normal \\
$0-20$ & 109 & 0.002 & 0.374 & 0.083 & 0.071 & 84.9 & 1.43 & 2.49 & Log normal \\
$20-40$ & 109 & 0.004 & 0.450 & 0.085 & 0.073 & 86.2 & 1.57 & 4.43 & Log normal \\
$40-60$ & 108 & 0.002 & 0.379 & 0.083 & 0.072 & 86.9 & 1.50 & 2.77 & Log normal \\
$60-80$ & 104 & 0.002 & 0.383 & 0.082 & 0.075 & 90.8 & 1.68 & 3.34 & Log normal \\
$80-100$ & 102 & 0.004 & 0.317 & 0.085 & 0.075 & 88.2 & 1.30 & 1.10 & Log normal \\
\hline
\end{tabular}

Note: $n$, sample number; SD, standard deviation; CV, coefficient of variation; DT, distribution type.

Figure 2 shows the differences in SWC under different categorical variables (land use, MAP and planting pattern) in various soil depths. SWC differed significantly in different land uses in the order of farmland $>$ grassland $>$ forestland $(P<0.05$; Fig. 2a). Farmland had the highest SWC $(0.163( \pm 0.072) \mathrm{g} / \mathrm{g})$ and forestland had the lowest $(0.049( \pm 0.035) \mathrm{g} / \mathrm{g})$ in the $0-100 \mathrm{~cm}$ soil depth. The higher value of SWC in farmland could be attributed to its geographical locations. The farmland is mainly distributed in the eastern regions of the Hexi Corridor where rainfall is higher, while the forestland is primarily distributed around the fringe of the Gobi desert in the northwest of the Hexi Corridor (Fig. 1). Compared with the farmland, the forestland and grassland more can easily form thicker dried layers in the subsoil profile (Wang et al., 2010a). There was no significant difference in SWC between soil depths within the same land use $(P>0.05)$.

The SWC decreased with MAP decreasing (Fig. 2b). The maximum value of SWC was 0.143 $( \pm 0.088) \mathrm{g} / \mathrm{g}$ under MAP $>300 \mathrm{~mm}$ and the minimum value was $0.063( \pm 0.063) \mathrm{g} / \mathrm{g}$ under $\mathrm{MAP}<100 \mathrm{~mm}$ in the $0-100 \mathrm{~cm}$ soil profile. The values of SWC in the upper soil layers $(0-20$, $20-40$ and $40-60 \mathrm{~cm}$ ) under MAP $>300 \mathrm{~mm}$ were significantly higher than those under MAP $<200$ $\mathrm{mm}$. The values of SWC in the upper soil layers $(0-20,20-40$ and $40-60 \mathrm{~cm})$ under MAP of 200-300 mm were significantly higher than those under MAP $<100 \mathrm{~mm}$. The results indicated that 

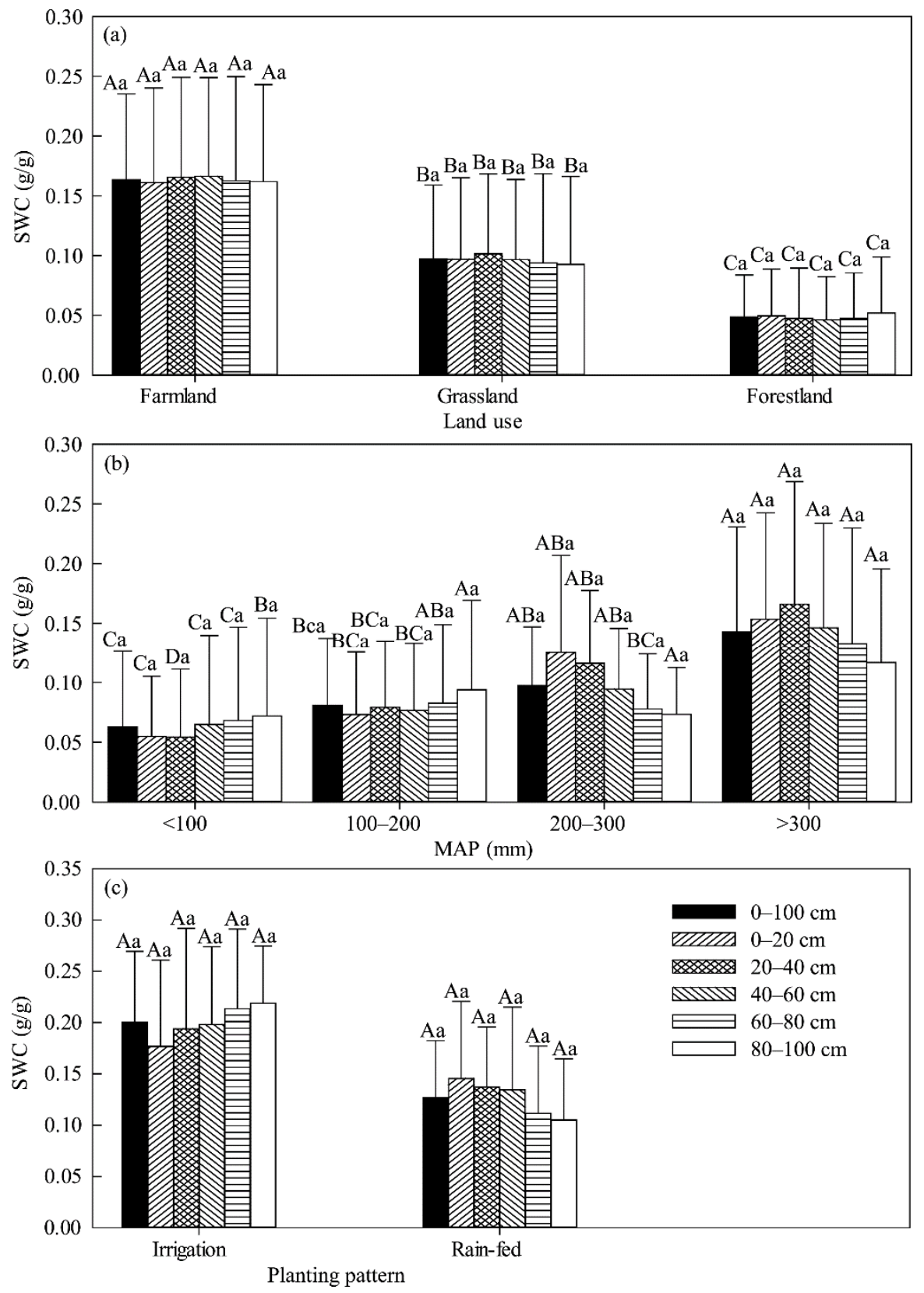

Fig. 2 Soil water content (SWC) under different land uses (a), MAP amounts (b) and planting pattern (c) in various soil depths across the Hexi Corridor. MAP, mean annual precipitation. Different capital letters indicate significant differences of SWC among different categorical variables in the same depth at the $P<0.05$ level. Different lowercase letters indicate significant differences of SWC among soil depths under the same categorical variable at the $P<0.05$ level.

there was a significant difference in SWC in the upper soil layers (0-20, 20-40 and 40-60 cm) when the MAP differed by $200 \mathrm{~mm}$. The MAP was the dominant driving factor determining the spatiotemporal patterns of SWC throughout the soil profile (Jia et al, 2017b). Previous researches indicated that SWC was significantly and positively correlated with MAP at the regional and transect scales (Zhang et al., 2017; Zhao et al., 2017; Zheng et al., 2017). Jin et al. (2011) and Liu et al. (2016) found that SWC had different dynamic patterns in zones with different MAP values. There was no significant difference in SWC between soil depths within the same MAP $(P>0.05)$.

Farmland is often irrigated to increase crop yield and biomass, especially in areas where natural 
water inputs are limited (Romero et al., 2015; Ran et al., 2017). However, irrigation activity did not significantly improve the SWC compared to the rain-fed farmland in our study (Fig. 2c). Since our sampling time was at least two days after irrigation, extensive evaporation and immediate water-uptake by the roots could have contributed to the insignificant difference in SWC between irrigated and rain-fed farmland (Wang et al., 2016).

\subsubsection{Geostatistical analysis}

The spatial structure of $\log$ transformed SWC was calculated (Table 2). The azimuth angle of principal anisotropic axis was $109^{\circ}-116^{\circ}$, which indicated that SWC had the largest spatial continuity in the northwest-southeast direction. The SWC showed a weak directional variation when the anisotropy ratio was less than 2.5 (Trangmar et al., 1986; Liu et al., 2013). Thus, only the isotropic semivariogram of SWC was calculated in various soil depths. In our study, the experimental semivariograms were best fitted by exponential models with lowest residual sum of squares (0.0371-0.1470) and highest coefficient of determination (0.487-0.898) in various soil depths.

Table 2 Semivariogram parameters for log transformed SWC in various soil depths across the Hexi Corridor

\begin{tabular}{cccccccccc}
\hline Depth $(\mathrm{cm})$ & Model & Nugget & Sill & Range $(\mathrm{km})$ & Nugget/sill ratio & $R^{2}$ & Residual SS & $\theta\left(^{\circ}\right)$ & Anisotropy ratio \\
\hline $0-100$ & Exponential & 0.107 & 0.853 & 168 & 0.125 & 0.835 & 0.0460 & 111 & 1.2 \\
$0-20$ & Exponential & 0.589 & 1.179 & 171 & 0.500 & 0.487 & 0.1470 & 116 & 1.0 \\
$20-40$ & Exponential & 0.057 & 1.109 & 153 & 0.051 & 0.838 & 0.0871 & 109 & 1.2 \\
$40-60$ & Exponential & 0.142 & 1.131 & 138 & 0.126 & 0.898 & 0.0371 & 118 & 1.1 \\
$60-80$ & Exponential & 0.161 & 1.056 & 75 & 0.152 & 0.722 & 0.0426 & 109 & 1.7 \\
$80-100$ & Exponential & 0.550 & 1.101 & 378 & 0.500 & 0.759 & 0.0631 & 113 & 1.3 \\
\hline
\end{tabular}

Note: $R^{2}$, coefficient of determination; Residual SS, residual sum of squares; $\theta$, azimuth angle of principal anisotropic axis (major direction with lower average semivariance); Anisotropic ratio=Rangemajor/Rangeminor at $\theta$ in anisotropic models.

The geostatistical parameters of SWC varied with soil depths without monotonous tendency. The ratio of nugget to sill was $0.051-0.152$ in the soil layers $(20-40,40-60$ and $60-80 \mathrm{~cm})$, indicating that the SWC showed a strong spatial dependence in these layers (Zhang et al., 2017). The spatial dependence of SWC was moderate with a ratio of nugget to sill 0.500 in the soil layers $(0-20$ and $80-100 \mathrm{~cm})$. The effective ranges varied from $75 \mathrm{~km}$ to $378 \mathrm{~km}$, which indicated that the SWC had a spatial dependence within a larger separation distance. As the effective range was much larger than our sampling interval (approximately $40 \mathrm{~km}$ ), the sampling system turn out to be adequate for detecting the spatial structure of SWC at a regional scale (Shao, 2006; Liu et al., 2013). The sill was similar and ranged from 1.056 to 1.179 in various soil depths, whereas the nuggets were larger $(>0.55)$ in the $0-20$ and $80-100 \mathrm{~cm}$ soil layers than in the $20-40,40-60$ and $60-80 \mathrm{~cm}$ soil layers $(<0.161)$. The high random variance in the surface and deeper soil layers could be attributed to the local heterogeneity (Hu et al., 2014).

The spatial distribution patterns of SWC interpolated by ordinary kriging method are shown in Figure 3. In general, the SWC decreased from southeast to northwest (Fig. 3a) and this trend corresponded to the precipitation gradient (Fig. 1). The SWC in the upper soil layers (0-20, 20-40 and 40-60 cm) decreased from south to north and showed similar patterns of variability as MAP (Figs. 1b-d). The SWC in the deeper layers $(60-80$ and $80-100 \mathrm{~cm}$ ) had an obvious horizontal variation trend in the west region of the Hexi Corridor (Figs. 3e and f). The middle area of the Hexi Corridor had a relative high SWC compared with other regions in various soil depths. This was mainly because that the middle area of the Hexi Corridor was dominated mainly by farmland and grassland with higher rainfall (Fig. 1). Moreover, the middle area was near the upper reaches of the Heihe River watershed, which has snow melt from the Qilian Mountains.

\subsection{Factors responsible for the spatial pattern of SWC}

Pearson's correlation coefficients between SWC and environmental variables are given in Table 3. The SWC increased with increasing LO and decreased with increasing LA, and the correlation coefficients decreased with increasing soil depth, which agreed with the results in Figure 3 . The 

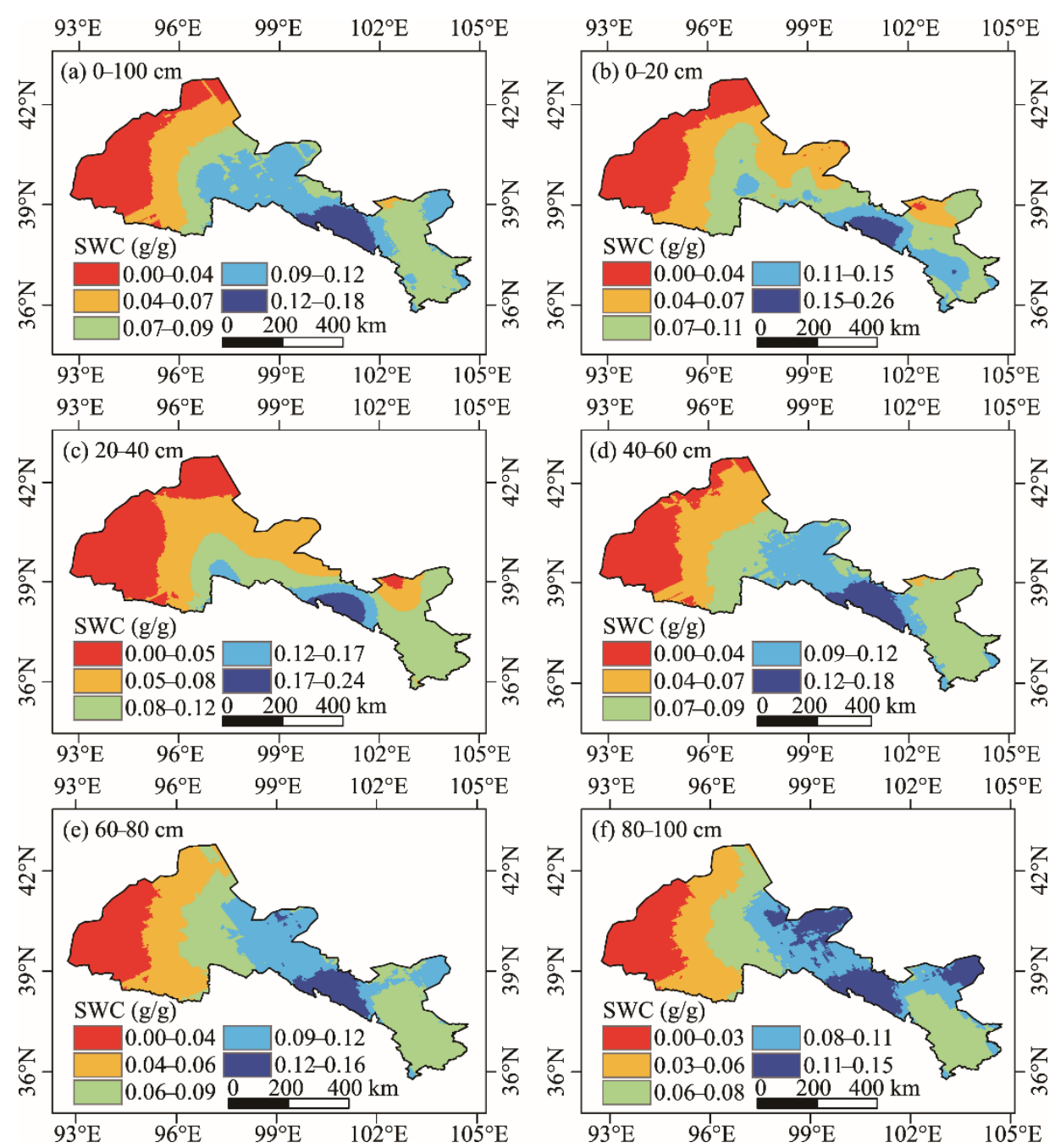

Fig. 3 Spatial pattern of SWC in various soil depths across the Hexi Corridor interpolated by ordinary kriging method. (a), 0-100 cm; (b), 0-20 cm; (c), 20-40 cm; (d), 40-60 cm; (e), 60-80 cm; (f), 80-100 cm.

SWC was positively correlated with EL only in the upper soil layers (0-20, 20-40 and 40-60 $\mathrm{cm}$ ). Though SWC has been found to be controlled by topography in small catchments (Qiu et al 2001; Huang et al., 2012), in this study it had no relationship with SG and SA in the whole soil profile except in the $20-40 \mathrm{~cm}$ soil layer at a regional scale. The SWC was significantly and positively correlated with $\mathrm{VC}(P<0.01)$ and the correlation coefficients ranged from 0.489 to 0.560 . Soil properties were significantly related to SWC $(P<0.01)$. The SWC was negatively correlated with $\mathrm{BD}$ and $\mathrm{Ks}$ and positively correlated with $\mathrm{FC}, \mathrm{CC}, \mathrm{SC}$ and SOC. The MAP was significantly correlated with SWC $(P<0.01)$, whereas PE had no correlation with SWC $(P>0.05)$. The mixed index AI showed a significant and negative correlation with SWC. The correlation coefficients between climatic variables (MAP and AI) and SWC decreased with increasing soil depth, indicating that the effect of climate on SWC decreases with increasing soil depth. Therefore, the spatial variation of SWC was more determined by local factors (such as soil properties) rather than climatic factors (such as PE) ( $\mathrm{Li}$ and Shao, 2015). The mean value of SWC $(0.083 \mathrm{~g} / \mathrm{g})$ was lower than the mean value of FC $(0.130 \mathrm{~g} / \mathrm{g})$ across the Hexi Corridor.

We used PCA method to extract eigenvectors and reduce dimensionality of continuous variables (Fig. 4). The variables which were not correlated with the SWC (Table 3) were excluded from the PCA. The PCA identified two to four principle components, which accounted for $69.4 \%-80.7 \%$ of the environmental variance in various soil depths. The first two principle 
components are shown in Figure 4. The PC 1 and PC 2 accounted for $45.3 \%-53.5 \%$ and $14.2 \%-20.5 \%$ of the total variance, respectively. The MAP had the highest factor loading in the PC 1 in various soil depths. The LO and LA had the highest factor loading in the PC 2 in the
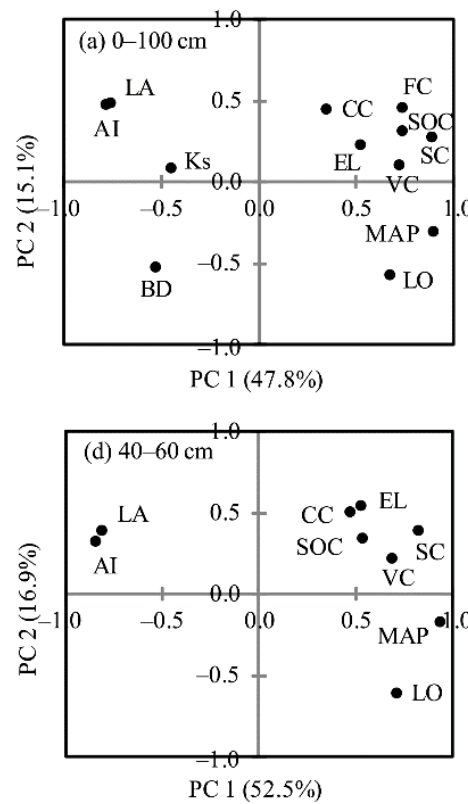
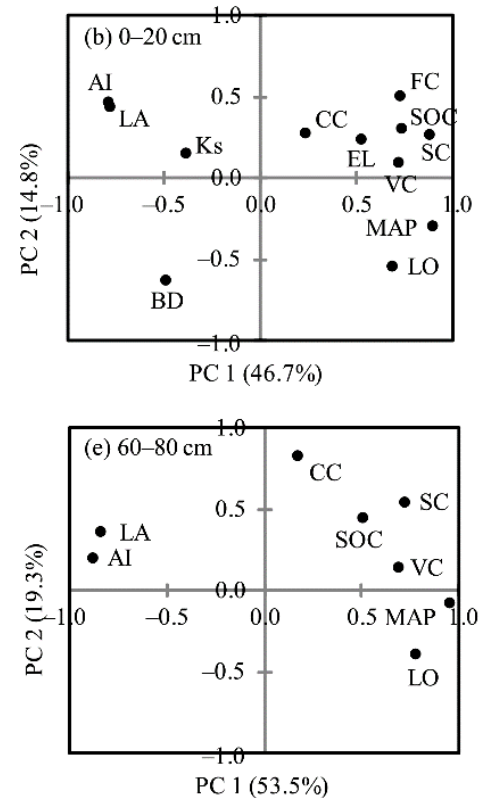
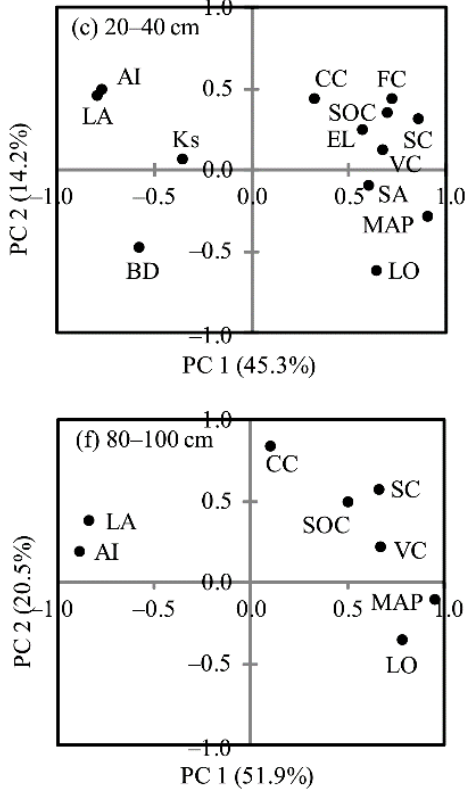

Fig. 4 Principle component analysis (PCA) of the significantly correlated factors with SWC in various soil depths. (a), 0-100 cm; (b), 0-20 cm; (c), 20-40 cm; (d), 40-60 cm; (e), 60-80 cm; (f), 80-100 cm. PC, principle component; PC 1, the first principle component; PC 2, the second principle component; LA, latitude; LO, longitude; EL, elevation; SG, slope gradient; SA, slope aspect; VC, vegetation coverage; $\mathrm{BD}$, soil bulk density; Ks, saturated hydraulic conductivity; FC, field capacity; CC, soil clay content; SC, soil silt content; SOC, soil organic carbon content; MAP, mean annual precipitation; PE, potential evaporation; AI, arid index.

Table 3 Correlation coefficients between SWC and related factors in various soil depths

\begin{tabular}{|c|c|c|c|c|c|c|}
\hline \multirow{2}{*}{ Factor } & \multicolumn{6}{|c|}{ Correlation coefficient } \\
\hline & $0-100 \mathrm{~cm}$ & $0-20 \mathrm{~cm}$ & $20-40 \mathrm{~cm}$ & $40-60 \mathrm{~cm}$ & $60-80 \mathrm{~cm}$ & $80-100 \mathrm{~cm}$ \\
\hline LA & $-0.298^{* *}$ & $-0.371^{* *}$ & $-0.367^{* *}$ & $-0.257^{* *}$ & $-0.195^{*}$ & -0.144 \\
\hline LO & $0.342^{* *}$ & $0.334^{* *}$ & $0.353^{* *}$ & $0.262^{* *}$ & $0.240^{*}$ & $0.245^{*}$ \\
\hline EL & $0.211^{*}$ & $0.328^{* *}$ & $0.297^{* *}$ & $0.192^{*}$ & 0.081 & -0.005 \\
\hline SG & 0.087 & 0.093 & 0.174 & 0.153 & 0.047 & 0.078 \\
\hline SA & 0.131 & 0.149 & $0.226^{*}$ & 0.180 & 0.075 & 0.076 \\
\hline $\mathrm{VC}$ & $0.589^{* *}$ & $0.534^{* *}$ & $0.560^{* *}$ & $0.552^{* *}$ & $0.508^{* *}$ & $0.489^{* *}$ \\
\hline $\mathrm{BD}$ & $-0.483^{* *}$ & $-0.548^{* *}$ & $-0.492^{* *}$ & - & - & - \\
\hline $\mathrm{Ks}$ & $-0.378^{* *}$ & $-0.365^{* *}$ & $-0.352^{* *}$ & - & - & - \\
\hline $\mathrm{FC}$ & $0.582^{* *}$ & $0.644^{* *}$ & $0.561^{* *}$ & - & - & - \\
\hline $\mathrm{CC}$ & $0.520^{* *}$ & $0.328^{* *}$ & $0.496^{* *}$ & $0.544^{* *}$ & $0.526^{* *}$ & $0.575^{* *}$ \\
\hline $\mathrm{SC}$ & $0.667^{* *}$ & $0.651^{* *}$ & $0.716^{* *}$ & $0.638^{* *}$ & $0.605^{* *}$ & $0.648^{* *}$ \\
\hline SOC & $0.705^{* *}$ & $0.678^{* *}$ & $0.723^{* *}$ & $0.635^{* *}$ & $0.685^{* *}$ & $0.646^{* *}$ \\
\hline MAP & $0.441^{* *}$ & $0.478^{* *}$ & $0.503^{* *}$ & $0.394^{* *}$ & $0.319^{* *}$ & $0.268^{* *}$ \\
\hline PE & -0.054 & -0.036 & -0.086 & -0.049 & -0.006 & 0.014 \\
\hline AI & $-0.368^{* *}$ & $-0.389^{* *}$ & $-0.401^{* *}$ & $-0.300^{* *}$ & $-0.282^{* *}$ & $-0.243^{*}$ \\
\hline
\end{tabular}

Note: LA, latitude; LO, longitude; EL, elevation; SG, slope gradient; SA, slope aspect; VC, vegetation coverage; BD, soil bulk density; Ks, saturated hydraulic conductivity; FC, field capacity; CC, soil clay content; SC, soil silt content; SOC, soil organic carbon content; MAP, mean annual precipitation; PE, potential evaporation; AI, arid index; -, not calculated. ${ }^{*}$, correlation is significant at the $P<0.05$ level (2-tailed). ${ }^{* *}$, correlation is significant at the $P<0.01$ level (2-tailed). 
0-100 cm soil profile (Fig. 4a). The BD was the main factor in the PC 2 in the $0-20 \mathrm{~cm}$ soil layer (Fig. 4b). The LO had the highest factor loading in the PC 2 in the 20-40 and 40-60 cm soil layers (Figs. 4c and d). The CC was the dominate factor in the PC 2 in the deeper soil layers (Figs. 4e and f). Vegetation coverage (VC) was not a good representative variable in all principle components. As all variables made a great contribution to the PC 1, we then used stepwise linear regression to further select variables that significantly affected the SWC.

Although many factors were significantly correlated with SWC, only some factors were included in the stepwise linear regression equations (Table 4). Generally, the VC, FC, LA, SOC and $\mathrm{CC}$ were the determining factors controlled SWC variation. The explanatory power $\left(R^{2}\right)$ of the equation was higher in the $0-20$ and $20-40 \mathrm{~cm}$ soil layers than that in the $40-60$ and $60-80$ $\mathrm{cm}$ soil layers, as some soil characteristics (BD, Ks, FC) were not measured in the deeper soil layers due to difficultly sampling in deep soils. The SOC and FC explained $64.4 \%$ of the variation of SWC in the $0-20 \mathrm{~cm}$ soil layer. Vegetation was the main factor affecting SWC variation in the 20-40, 40-60 and 60-80 cm layers. The CC has been found to control the spatial patterns of SWC in the deeper soil layers at large scales (Li et al., 2015). These results indicated that vegetation and soil texture were the two main factors determining the SWC in arid and semi-arid areas of the Hexi Corridor. Soil properties (CC) was the main factor responsible for SWC in the deeper soil layers $(80-100 \mathrm{~cm})$.

Table 4 Stepwise linear regression equation between SWC and related factors in various soil depths

\begin{tabular}{clrrr}
\hline Depth $(\mathrm{cm})$ & \multicolumn{1}{c}{ Equation } & $R^{2}$ & $n$ & $P$ \\
\hline $0-100$ & SWC $=0.689 \times \mathrm{VC}$ & 0.468 & 86 & $<0.001$ \\
& $\mathrm{SWC}=0.515 \times \mathrm{VC}+0.349 \times \mathrm{FC}$ & 0.556 & 86 & $<0.001$ \\
& $\mathrm{SWC}=0.59 \times \mathrm{VC}+0.393 \times \mathrm{FC}+0.217 \times \mathrm{LA}$ & 0.588 & 86 & $<0.001$ \\
\multirow{2}{*}{$0-20$} & $\mathrm{SWC}=0.455 \times \mathrm{VC}+0.337 \times \mathrm{FC}+0.218 \times \mathrm{LA}+0.225 \times \mathrm{SOC}$ & 0.605 & 86 & $<0.001$ \\
& $\mathrm{SWC}=0.726 \times \mathrm{SOC}$ & 0.522 & 104 & $<0.001$ \\
\multirow{2}{*}{$20-40$} & $\mathrm{SWC}=0.492 \times \mathrm{SOC}+0.425 \times \mathrm{FC}$ & 0.644 & 104 & $<0.001$ \\
& $\mathrm{SWC}=0.706 \times \mathrm{VC}$ & 0.492 & 74 & $<0.001$ \\
\multirow{2}{*}{$40-60$} & $\mathrm{SWC}=0.539 \times \mathrm{VC}+0.398 \times \mathrm{FC}$ & 0.619 & 74 & $<0.001$ \\
$60-80$ & $\mathrm{SWC}=0.382 \times \mathrm{VC}+0.308 \times \mathrm{FC}+0.304 \times \mathrm{SOC}$ & 0.664 & 74 & $<0.001$ \\
& $\mathrm{SWC}=0.658 \times \mathrm{VC}$ & 0.426 & 90 & $<0.001$ \\
$80-100$ & $\mathrm{SWC}=0.527 \times \mathrm{VC}$ & 0.269 & 85 & $<0.001$ \\
& $\mathrm{SWC}=0.505 \times \mathrm{VC}+0.221 \times \mathrm{CC}$ & 0.305 & 85 & $<0.001$ \\
& $\mathrm{SWC}=0.566 \times \mathrm{CC}$ & 0.312 & 83 & $<0.001$ \\
& $\mathrm{SWC}=0.500 \times \mathrm{CC}+0.427 \times \mathrm{VC}$ & 0.485 & 83 & $<0.001$ \\
\hline
\end{tabular}

Note: The coefficients of variables in the equations are the standardized coefficients (path coefficients).

\section{Conclusions}

Knowledge of SWC helps improve water resource regulation and vegetation restoration, and is also important for economic and social development, especially in water-limited areas in Northwest China. This study conducted a large-scale field investigation to analyze the spatial patterns of SWC and its related factors across the Hexi Corridor. The results showed that SWC decreased from the southeast to northwest regions of the Hexi Corridor, following the precipitation gradient. Farmland, which was distributed in the eastern region, had the highest SWC, followed by grassland and forestland. The SWC had similar patterns of variation in various soil depths. MAP had the highest factor loading in the first principal component. Geographical position (longitude and latitude) and soil properties (soil bulk density and soil clay content) were the main factors that explained the variance of SWC in the second principal component. Local factors, which were determined by soil texture, SOC, FC and VC, were responsible for the spatial variability of SWC in the arid and semi-arid areas of the Hexi Corridor. 


\section{Acknowledgements}

This research was sponsored by the National Natural Science Foundation of China $(41530854,41571130081)$. We thank the anonymous reviewers and the editors for their constructive suggestions. We also thank GUO Zhenxue and YANG Lianqi for their help in field sampling.

\section{References}

Bao C, Fang C L. 2007. Water resources constraint force on urbanization in water deficient regions: A case study of the Hexi Corridor, arid area of NW China. Ecological Economics, 62(3-4): 508-517.

Bao S D. 2000. Soil Agro-Chemistrical Analysis. Beijing: China Agriculture Press, 30-33. (in Chinese)

Cheng G D, Xin L, Zhao W Z, et al. 2014. Integrated study of the water-ecosystem-economy in the Heihe River Basin. National Science Review, 1(3): 413-428.

Deng L, Yan W M, Zhang Y W, et al. 2016. Severe depletion of soil moisture following land-use changes for ecological restoration: Evidence from northern China. Forest Ecology and Management, 366: 1-10.

$\mathrm{Hu}$ W, Shao M A, Wan L, et al. 2014. Spatial variability of soil electrical conductivity in a small watershed on the Loess Plateau of China. Geoderma, 230-231: 212-220.

Huang Y L, Chen L D, Fu B J, et al. 2012. Effect of land use and topography on spatial variability of soil moisture in a gully catchment of the Loess Plateau, China. Ecohydrology, 5(6): 826-833.

Jia X X, Shao M A, Zhu Y J, et al. 2017a. Soil moisture decline due to afforestation across the Loess Plateau, China. Journal of Hydrology, 546: 113-122.

Jia X X, Shao M A, Zhao C L, et al. 2017b. Spatiotemporal characteristics of soil water storage along regional transect on the Loess Plateau, China. Clean-Soil Air Water, 45.

Jin T T, Fu B J, Liu G H, et al. 2011. Hydrologic feasibility of artificial forestation in the semi-arid Loess Plateau of China. Hydrology and Earth System Sciences, 15: 2519-2530.

Klute A, Dirksen, C. 1986. Hydraulic conductivity and diffusivity: laboratory methods. In: Klute A. Methods of Soil Analysis, Part 1, Physical and Mineralogical Methods. Madison: American Society of Agronomy, 694-700.

Li D F, Shao M A. 2015. Temporal stability of soil water storage in three landscapes in the middle reaches of the Heihe River, northwestern China. Environmental Earth Sciences, 73(7): 3095-3107.

Li M X, Ma Z G. 2015. Soil moisture drought detection and multi-temporal variability across China. Science China Earth Sciences, 58(10): 1798-1813.

Li X Z, Shao M A, Jia X X, et al. 2015. Depth persistence of the spatial pattern of soil-water storage along a small transect in the Loess Plateau of China. Journal of Hydrology, 529: 685-695.

Liu C Z. 2003. The vulnerability of water resources in Northwest China. Journal of Glaciology and Geocryology, 25(6): 309-314.

Liu Y X, Zhao W W, Wang L X, et al. 2016. Spatial variations of soil moisture under Caragana korshinskii Kom. from different precipitation zones: field based analysis in the Loess Plateau, China. Forests, 7(2): 31.

Liu Z P, Shao M A, Wang Y Q. 2013. Spatial patterns of soil total nitrogen and soil total phosphorus across the entire Loess Plateau region of China. Geoderma, 197-198: 67-78.

McColl K A, Alemohammad S H, Akbar R, et al. 2017. The global distribution and dynamics of surface soil moisture. Nature Geoscience, 10: 100-104.

Mollnau C, Newton M, Stringham T. 2014. Soil water dynamics and water use in a western juniper (Juniperus occidentalis) woodland. Journal of Arid Environments, 102: 117-126.

Moore G W, Jones J A, Bond B J. 2011. How soil moisture mediates the influence of transpiration on streamflow at hourly to interannual scales in a forested catchment. Hydrological Processes, 25(24): 3701-3710.

Niu Y, Cheng C X, Li X Y, et al. 2016. The relation between plant growth and soil water in desert district of Hexi Corridor. Journal of Glaciology and Geocryology, 1417-1424. (in Chinese)

Orth R, Seneviratne S I. 2017. Variability of soil moisture and sea surface temperatures similarly important for warm-season land climate in the community earth system model. Journal of Climate, 30: 2141-2162.

Qiu Y, Fu B J, Wang J, et al. 2001. Soil moisture variation in relation to topography and land use in a hillslope catchment of the Loess Plateau, China. Journal of Hydrology, 240(3-4): 243-263.

Ran H, Kang S Z, Li F S, et al. 2017. Responses of water productivity to irrigation and N supply for hybrid maize seed production in an arid region of Northwest China. Journal of Arid Land, 9(4): 504-514.

Ratliff L F, Ritchie J T, Cassel D K. 1983. Field-measured limits of soil water availability as related to laboratory-measured 
properties. Soil Science Society of America Journal, 47(4): 770-775.

Romero P, MuñozR G, Fernandez-Fernandez, et al. 2015. Improvement of yield and grape and wine composition in field-grown Monastrell grapevines by partial root zone irrigation, in comparison with regulated deficit irrigation. Agricultural Water Management, 149: 55-73.

Seneviratne S I, Corti T, Davin E L, et al. 2010. Investigating soil moisture-climate interactions in a changing climate: a review. Earth-Science Reviews, 99(3-4): 125-161.

Shao M A, Wang Q J, Huang M B. 2006. Soil Physics. Beijing: Higher Education Press, 228-261. (in Chinese)

Sonnenborg T O, Christiansen J R, Pang B, et al. 2017. Analyzing the hydrological impact of afforestation and tree species in two catchments with contrasting soil properties using the spatially distributed model MIKE SHE SWET. Agricultural and Forest Meteorology, 239: 118-133.

Sun T, Liu S Z, Ji Y F, et al. 2017. Evaluation of the hydrological status and water quality in the gobi areas of Hexi Corridor, Gansu Province. Journal of Lanzhou University: Natural Sciences, 53(4): 494-500. (in Chinese)

Trangmar B B, Yost R S, Uehara G. 1986. Application of geostatistics to spatial studies of soil properties. Advances in Agronomy, 38: 45-94.

Wang L, Cheung K K W. 2017. Potential impact of reforestation programmes and uncertainties in land cover effects over the loess plateau: a regional climate modeling study. Climatic Change, 144(3): 475-490.

Wang M, Su Y, Yang X. 2014. Spatial distribution of soil organic carbon and its influencing factors in desert grasslands of the Hexi Corridor, Northwest China. PloS One, 9(4): e94652.

Wang Y Q, Shao M A, Liu Z P. 2010a. Large-scale spatial variability of dried soil layers and related factors across the entire Loess Plateau of China. Geoderma, 159(1-2): 99-108.

Wang Y Q, Shao M A, Shao H B. 2010b. A preliminary investigation of the dynamic characteristics of dried soil layers on the Loess Plateau of China. Journal of Hydrology, 381(1-2): 9-17.

Wang Y Q, Shao M A, Liu Z P. 2013. Vertical distribution and influencing factors of soil water content within 21-m profile on the Chinese Loess Plateau. Geoderma, 193-194: 300-310.

Wang Z S, Cai H J, YU L Y, et al. 2016. Estimation of evapotranspiration and soil evaporation of winter wheat in arid region of Northwest China based on SIMDualKC model. Transactions of the Chinese Society of Agricultural Engineering, 32(5): 126-136. (in Chinese)

Wu L L. 2016. Study on optimal layout of ecological network of oasis in Hexi Corridor. PhD Dissertation. Lanzhou: Gansu Agricultural University, 11-15. (in Chinese)

Wu Y Z, Huang M B, Warrington D N. 2015. Black locust transpiration responses to soil water availability as affected by meteorological factors and soil texture. Pedosphere, 25(1): 57-71.

Xia J, Ning L, Wang Q, et al. 2017. Vulnerability of and risk to water resources in arid and semi-arid regions of West China under a scenario of climate change. Climatic Change, 144(3): 549-563.

Yao Y Y, Zheng C M, Tian Y, et al. 2018. Eco-hydrological effects associated with environmental flow management: A case study from the arid desert region of China. Ecohydrology, 11(1): e1914.

Zhang C C, Shao M A, Jia X X. 2017. Spatial continuity and local conditions determine spatial pattern of dried soil layers on the Chinese Loess Plateau. Journal of Soils and Sediments, 17(8): 2030-2039.

Zhang C X, Wang X M, Dong Z B, et al. 2017. Aeolian process of the dried-up riverbeds of the Hexi Corridor, China: a wind tunnel experiment. Environmental Monitoring and Assessment, 189: 419.

Zhang K, Su Y Z, Yang R. 2017. Biomass and nutrient allocation strategies in a desert ecosystem in the Hexi Corridor, northwest China. Journal of Plant Research, 130(4): 699-708.

Zhang S P, Shao M A, Li D F. 2017. Prediction of soil moisture scarcity using sequential Gaussian simulation in an arid region of China. Geoderma, 295: 119-128.

Zhang Y W, Deng L, Yan W M, et al. 2016. Interaction of soil water storage dynamics and long-term natural vegetation succession on the Loess Plateau, China. Catena, 137: 52-60.

Zhao C L, Shao M A, Jia X X, et al. 2017. Estimation of spatial variability of soil water storage along the south-north transect on China's Loess Plateau using the state-space approach. Journal of Soils and Sediments, 17(4): 1009-1020.

Zhao T B, Dai A G. 2017. Uncertainties in historical changes and future projections of drought. Part II: model-simulated historical and future drought changes. Climatic Change, 144(3): 535-548.

Zheng Z Y, Ma Z G, Li M X, et al. 2017. Regional water budgets and hydroclimatic trend variations in Xinjiang from 1951 to 2000. Climatic Change, 144: 447-460. 